\section{Interstitial deletion of the long arm of chromosome 5: 46,XX,del(5) (q13q22)}

The patient was delivered after a normal pregnancy to a primigravida mother in February 1981. Her parents were healthy and non-consanguineous. They were 25 years old at her birth. Her birth weight was $2980 \mathrm{~g}$.

Physical examination revealed the following abnormalities (fig 1): coarse and abundant hair, narrow forehead with hypertrichosis, flat occiput, hypertelorism, short nose with anteverted nostrils, a large philtrum with a deep groove, cleft palate, retromicrognathia, simply formed auricle on the right, imperforate anus with rectoperineal fistula, camptodactyly of the right third finger and left second finger, and bilateral pes adductus. Cardiac murmur was not heard.

Dermatoglyphic study showed the finger patterns to consist of eight whorls and two ulnar loops on both fifth fingers; atd angles were $60^{\circ}$ on both palms. Whorls vere observed in the hypothenar areas bilaterally. There was a single transverse flexion crease on her left palm with a transitional crease on her right palm.

Routine blood investigations, including serum electrolytes, protien, and immunoglobulin level, and urine analysis were normal. Chest $\boldsymbol{x}$-ray and electrocardiogram were also normal. A CT scan of the brain showed slight dilation of the anterior horns of the lateral ventricles.

Lymphocyte karyotype was 46,XX,del(5)(q13q22) (fig 2). Both parents had a normal karyotype.

Approximate'y 7 months after birth her developmental quotient was about 15 . Height was $61.0 \mathrm{~cm}$ (-2.7 SD), weight was $3955 \mathrm{~g}(-4.5 \mathrm{SD})$, and head circumference was $39.5 \mathrm{~cm}$ (-2.9SD).

There have been five reports ${ }^{1-3}$ on interstitial deletion of the long arm of chromosome 5, with detailed clinical

Received for publication 28 May 1982.

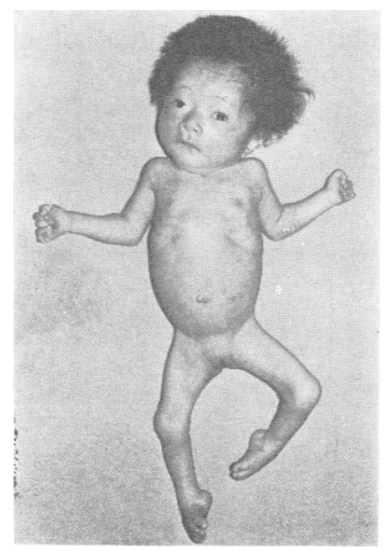

FIG 1 Clinical features of the patient.

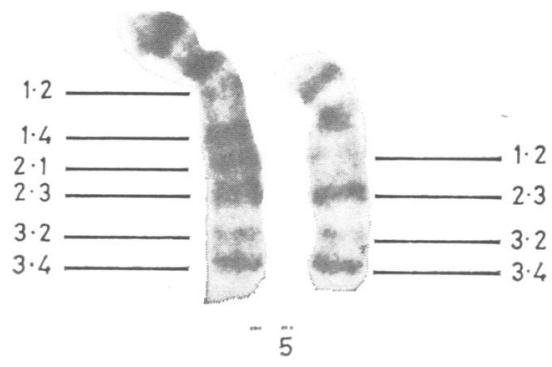

FIG 2 G banded partial karyotype of chromosome 5.

findings reported in two cases. ${ }^{2}{ }^{3}$ However, the clinical pictures in these two reports were different from each other. ${ }^{3}$ This may be the result of the difference in the size of deletion in the two cases, but we feel that difference in age at the time of diagnosis is more likely to be responsible, because the face and some minor anomalies change with age.

In at least two of the three cases under consideration, the following signs were found in common: intrauterine growth retardation was not evident; weight gain was greatly retarded; mental development was greatly retarded; the head was brachycephalic and the hair was coarse and abundant; narrow forehead, epicanthus, anteverted nostrils, a large philtrum with a deep groove, and retromicrognathia were observed; the neck was short; pes adductus was observed; and the majority of the fingers had whorls.

Shozo OHDo,

HARUMICHI MADOKORO, AND Kunio Hayakawa

Department of Pediatrics, Miyazaki Medical College, 5,200 Kihara,Kiyotake-cho, Miyazaki-gun, Miyazaki 889-16, Japan.

\section{References}

1 Kucerova M, Polivkova Z. 46,XX,del (5) (pter to q15 ::q22 to qter). In: Borgaonkar DS, Lillard DR, eds. Respository of chromosomal variants and anomalies in man. Fifth listing. Denton, Texas: North Texas University, 1978:56.

2 Pescia G, Gaide AC, Juillard E. Syndrome dismorphique, débilité mentale et délétion interstitielle des bras longs d'un chromosome 5. Ann Genet (Paris) 1978;21:161-3.

3 Stoll C, Levy JM, Roth MP. Interstitial deletion of the long arm of chromosome 5 in a deformed boy: 46,XY, del (5) (q13q15). J Med Genet 1980;17:486-7.

Requests for reprints to Dr S Ohdo, Department of Pediatrics, Miyazaki Medical College, 5,200 Kihara, Kiyotake-cho, Miyazaki-gun, Miyazaki 889-16, Japan. 